\title{
A SUPERAÇÃO DA POLÍTICA DA MONETIZAÇÃO DO RISCO E A INSALUBRIDADE: UMA ÓTICA COMPARATIVA APRESENTADA PELO DIREITO ITALIANO
}

\author{
OVERCOMING THE POLICY OF RISK MONITORING AND UNDERHOLDANCE: \\ A COMPARATIVE VIEW PRESENTED BY ITALIAN LAW
}

\section{SUPERANDO LA POLÍTICA DE MONITOREO Y SUBALTAZACIÓN DE RIESGOS: UNA VISIÓN COMPARATIVA PRESENTADA POR LA LEY ITALIANA}

\begin{abstract}
Marco Antônio CÉsAr ViLlatore
http://orcid.org/0000-0001-6365-6283 / http://lattes.cnpq.br/6658857270253086 / marcovillatore@gmail.com Doutor em Diritto del Lavoro, Sindacale e della Previdenza Sociale pela Università degli Studi di Roma I, La Sapienza, revalidado pela UFSC. Professor do Mestrado e do Doutorado em Direito da PUCPR. Professor da UNINTER. Professor Adjunto II, licenciado sem remuneração, da UFSC. Advogado. Curitiba, PR, Brasil.

\section{MIRIAM OLIVIA KNOPIK FERRAZ}

http://orcid.org/0000-0002-3350-5502 / http:// lattes.cnpq.br/4312339156293623 / m.okf@hotmail.com Mestranda em Direito pela PUCPR (Bolsista CAPES). Pós-graduanda em Direito Constitucional pela ABDConst Advogada. Curitiba, PR, Brasil.
\end{abstract}

\begin{abstract}
RESUMO
O estudo se desenvolve da análise completa da política da monetização do risco, para posteriormente adentrar no Direito Italiano, construindo uma análise comparada entre as principais normativas de ambos os países (Brasil e Itália). A análise desta política, no Brasil e quanto à insalubridade, demonstra-se extremamente arcaica e passível de superação quando observadas as políticas atuais de prevenção e eliminação do risco no ambiente laboral. Ainda, os custos sociais a que esta política se vincula demonstram reflexos na sociedade de forma ampla que se somam à desatualização da legislação brasileira a parâmetros mínimos internacionais. Em contrapartida, o direito italiano busca o enfoque preventivo e traz uma legislação completa e com atualizações e reformas, no mínimo, anuais. 0 objetivo é estudar se a normativa italiana pode trazer complementações à legislação brasileira, no que os ordenamentos se assemelham e onde se diferenciam. Para esta análise, realiza-se o contraponto de ambas as Constituições, a CLT e o Código Civil Italiano, e da NR nº 15 do MTE no Brasil e o decreto nº 81/2008 da Itália.
\end{abstract}

Palavras-chave: Política da Monetização do Risco; Insalubridade; Itália; Brasil; Direito do Trabalho.

\section{ABSTRACT}

The study develops from the complete analysis of the risk monetization policy, to enter later into Italian law, constructing a comparative analysis between the main regulations of both countries (Brazil and Italy). The analysis of this policy, in Brazil and regarding insalubrity, is extremely archaic and can be overcomed when the current policies of prevention and elimination of risk in the work environment are observed. Moreover, the social costs to which this policy is linked show a reflex in society in a broad way that is added to the outdated Brazilian legislation to minimum international parameters. On the other hand, Italian law seeks a preventive approach, and brings complete legislation with at least annual updates and reforms. The objective is to study if the Italian legislation can bring complementarities to the Brazilian legislation, in what the ordinances are similar and where they differ. For this 
A SUPERAÇÃO DA POLÍTICA DA MONETIZAÇÃO DO RISCO E A INSALUBRIDADE: UMA ÓTICA COMPARATIVA APRESENTADA PELO DIREITO ITALIANO

MARCO ANTÔNIO CÉSAR VILLATORE MIRIAM OLIVIA KNOPIK FERRAZ

analysis the counterpoint of both constitutions, the CLT and the Italian Civil Code, and NR no. 15 of the MTE in Brazil and decree no. $81 / 2008$ of Italy.

Keywords: Risk Monetization Policy; Unhealthiness; Italy; Brazil; Labor Law.

\section{RESUMEN}

La fosfoetanolamina sintética, conocida popularmente como "píldora del cáncer", se convierte en un campo de análisis empírico por las controversias sobre la liberación de esta sustancia como medicamento. Frente a la incertidumbre científica sobre su eficacia y seguridad varios fueron los posicionamientos tomados, ya sea irregularmente distribuida o cuestionada judicialmente, ya sea liberada por ley o nuevamente suspendida. En escenarios de incertidumbre como este, que desembocan en la ciencia del Derecho, el principio de la precaución ampara el proceso decisorio. Ante ello, se pretende comprender cómo el caso de la sustancia en cuestión, elucida la problemática proveniente de la concentración en instrumentos de gestión sobre la precaución que mantiene inoperativos esquemas de gobernanza. La investigación es amparada por el método deductivo, siendo empleadas la investigación bibliográfica y documental, conjugada con el estudio de caso. En este recorrido, se comprobó lo ambigua y conturbada que la arena decisoria puede revelarse sin que haya el establecimiento de parámetros cautelares orientados por un proceso de gobernanza.

Palabras clave: Fosfoetanolamina; Gestión; Gobernanza; Precaución.

\section{SUMÁRIO}

INTRODUÇAO; 1. POLÍTICA DA MONETIZAÇÃO DO RISCO; 2. APLICABILIDADE E ABRANGÊNCIA NO DIREITO BRASILEIRO; 3.DO DIREITO COMPARADO: DA ITÁLIA AO BRASIL; 3.1 Constituições; 3.2 Consolidação das Leis do Trabalho brasileira e Código Civil italiano; 3.3 Norma Regulamentadora $n^{\circ}$. 15 do MTE brasileira e Decreto $n^{\circ}$. 81/2008 italiano e legislações esparsas; 3.3.1 Serviços de Prevenção e Proteção; 4.3.2 Proteção Individual; 3.3.3 Construção; 3.3.4. Ruído; 3.3.5 Vibração; 3.3.6 Eletromagnético; 3.3.7 Radiações; 3.3.8 Agentes Cancerígenos; 3.3.9 Agentes biológicos; 3.3.10 Local úmido; 3.3.11 Trabalho submerso; 3.3.12 Trabalho sob ar comprimido; 3.3.13 Baixas temperaturas; 3.3.14 Anexos específicos; 4. NECESSIDADE DE REFORMULAÇÃO; CONCLUSÃO; REFERÊNCIAS.

\section{INTRODUÇÃO}

O meio ambiente de trabalho possui diversas proteções no Brasil e internacionalmente, um conceito que cresceu e mantém uma projeção em ascensão quanto à tutela de direitos, e esta definição influencia diretamente nos ideais de pleno emprego e principalmente nas condições de salubridade laboral. É através do estudo dessas relações que se denota a importância da prevenção e construção de um meio ambiente saudável, em detrimento de políticas de lucro exacerbado e exploração máxima.

Dois rumos são possíveis para a solução desse conflito: a remuneração, como único método, ou muitas vezes com ínfimas políticas preventivas atreladas, resultando na monetização da saúde do trabalhador e a sua consequente barganha ou a primazia pela prevenção e formação de condições laborais propícias ao desenvolvimento do ser humano e sua dignidade. O Brasil 
A SUPERAÇÃO DA POLÍTICA DA MONETIZAÇ̃̃O DO RISCO E A INSALUBRIDADE: UMA ÓTICA COMPARATIVA APRESENTADA PELO DIREITO ITALIANO

MARCO ANTÔNIO CÉSAR VILLATORE MIRIAM OLIVIA KNOPIK FERRAZ

estagnou na questão da insalubridade e dos riscos ocupacionais: na política da monetização do risco.

Transpondo a realidade internacional, a Itália é um dos países precursores no desenvolvimento do Direito do Trabalho, que transcorreu desde a Encíclica Católica Rerum Novarum (1891) do Papa Leão XIII até os dias de hoje. A normativa italiana se destaca, ainda, pela predominância de uma política prevencionista, de maior controle, especificidade e com constantes atualizações. Ambos os países, Brasil e Itália, assemelham-se por possuírem construções baseadas em extensas normativas e estruturas similares com a elevação do patamar constitucional, legislações infraconstitucionais e normativas suplementares mais específicas, e, assim, a análise comparada de ambos os ordenamentos se torna possível.

Com a construção das realidades de ambos os países, comparam-se de maneira ampla e detalhada as principais regulamentações de ambos os ordenamentos sobre a insalubridade, ou seja, em paralelo, estudam-se Constituições, a CLT e o Código Civil Italiano, e como principais fontes normativas, a Norma regulamentadora $n^{\circ} .15$ do MTE no Brasil e o decreto $n^{\circ} .81 / 2008$, intitulado como "Testo unico sulla salute e sicurezza sul lavoro" da Itália. Acrescentam-se ainda diversas legislações esparsas para a complementação normativa, quando ausente nesses dois principais institutos. 0 objetivo desta análise é estudar onde se encontram as diferenças dos ordenamentos, a possibilidade de transposição de institutos normativos italianos para o Brasil e como se dão esses institutos diante da realidade fática.

\section{POLÍTICA DA MONETIZAÇÃO DO RISCO}

A política da monetização do risco pode ser sintetizada na possibilidade de o trabalhador colocar à disposição a sua saúde, recebendo, em contrapartida, um bônus pecuniário. ${ }^{1}$ A grande problemática dessa política é que possui como argumentos fortalecedores as afirmativas de que, quando uma atividade é naturalmente considerada de risco, não haveria soluções e alternativas para a redução e a eliminação, ou que o trabalhador é livre para procurar outra atividade, que não envolva essa exposição indesejada, o que vai de encontro às reais situações vividas pelos trabalhadores. ${ }^{2} \mathrm{Na}$ realidade, essa liberdade não se demonstra plena e

\footnotetext{
${ }^{1}$ BARROS, Alice Monteiro de. Curso de direito do trabalho. 9. ed. São Paulo: LTr, 2013. p. 841 e 842.

2 LIEBER, Renato Rocha. Saúde do Trabalho Rumo ao Ano 2000: Tendência na Avaliação dos Ambientes de Trabalho. Revista Brasileira de Saúde Ocupacional, v.19, no 74. São Paulo: FUNDACENTRO, 1991, p. 52 a 60. Disponível em: <https://goo.gl/WByK3R>. Acesso em: 14 de janeiro de 2017.
} 
A SUPERAÇÃO DA POLÍTICA DA MONETIZAÇ̃̃O DO RISCO E A INSALUBRIDADE: UMA ÓTICA COMPARATIVA APRESENTADA PELO DIREITO ITALIANO

MARCO ANTÔNIO CÉSAR VILLATORE MIRIAM OLIVIA KNOPIK FERRAZ

muito menos plausível de ser admitida, uma vez que, cada vez mais, o mercado de trabalho se mostra inflado, e as dificuldades aumentam quando os candidatos não possuem uma qualificação profissional sólida, o que leva à submissão a condições inaceitáveis de labor.

Além disso, a própria noção de aposentadoria especial dada aos trabalhadores que se submetem a essas condições de trabalho serve como um estímulo a essa política, já que, na perspectiva do empregado, ao laborar em um ambiente insalubre ou perigoso, ele terá um aumento de sua remuneração e, ainda, poderá se aposentar mais brevemente, o que, diante da realidade social vivida, traz uma falácia da alternativa "viável e pecuniariamente benéfica": a renúncia à saúde.

Essa política tem como fulcro principal o correto pagamento de adicionais ou indenizações e não a priorização na eliminação ou redução do fator de risco. Mesmo quando há a possibilidade de redução através de estudos e determinações legais, a falta de interesse é nítida no Estado, nos empregadores e até nos próprios empregados representados pelos seus sindicatos, que muitas vezes se encontram distantes das causas das doenças profissionais. ${ }^{3}$

Denota-se que a política da monetização do risco abrange muito mais do que apenas os empregadores. É pensada e aplicada pelos mais diversos institutos que norteiam, e mesmo quem deveria proteger não visualiza a real necessidade de seus protegidos: a eliminação ou redução dos agentes agressivos e a verdadeira melhora do ambiente laboral. Afinal, optar pela recompensa monetária desvia da preocupação central, que é a saúde do trabalhador. ${ }^{4}$

É evidente a ausência de iniciativas do Poder Judiciário quanto a isso, sendo que, diante de seu papel, poderia ao menos notificar os órgãos públicos responsáveis para que tomem providências, como, por exemplo, a Superintendência Regional do Trabalho e Emprego, o Ministério do Trabalho e Emprego ou o próprio Ministério Público do Trabalho, e, este último, em virtude de suas prerrogativas, deve ter uma atuação mais próxima das realidades e problemas sociais enfrentados pelos empregados, independente de provocação. Neste mesmo sentido estão as palavras de Renato Nalini, quando trata que as políticas públicas não conferem ao meio ambiente a importância devida, sendo a função do magistrado, além da aplicação da lei ao caso concreto, a de concretizador das promessas do constituinte. ${ }^{5}$

\footnotetext{
${ }^{3}$ MINC, Carlos. A ecologia nos barrancos da cidade. In: VIANA, G.; SILVA, M.; DINIZ, N.(orgs). O desafio da sustentabilidade: um debate socioambiental no Brasil. São Paulo: Ed. Fundação Perseu Abramo, 2001.

${ }^{4}$ OLIVEIRA, Sebastião Geraldo de. Proteção Jurídica à Saúde do Trabalhador. 6a ed. São Paulo: LTr, 2011.

${ }^{5}$ NALINI, José Renato. O Juiz e a Constituição Ecológica. In: NALINI, José Renato (Coordenador). Juízes Doutrinadores. São Paulo: Millenium, 2008, p. 47.
} 


\section{APLICABILIDADE E ABRANGÊNCIA NO DIREITO BRASILEIRO}

Os primeiros traços da aplicação da teoria da monetização do risco no Direito brasileiro se deram através do Decreto-Lei $n^{\circ}$. 2.162\1940, que instituiu os adicionais em graduações de $40 \%$, 20\% e 10\% sobre o salário mínimo, de acordo com as variações de exposição. Na época do surgimento da lei não havia muitas previsões, principalmente no âmbito interno, acerca da prevenção de acidentes e doenças ocupacionais. Somente em 1978, com a vigência do NR-15 ${ }^{6}$ é que se iniciaram estudos e demandas acerca dos limites e condições de exposição.

Realizando uma análise restrita ao ambiente laboral e à realidade brasileira, denota-se que os estudos a respeito dessa questão adotam duas formas de contenção do problema: primeiramente, as regras, principalmente as presentes no NR-15, que dizem respeito à contenção, à neutralização e à eliminação de acidentes e doenças do trabalho, e em paralelo, as que têm o objetivo da oneração do empregador, através do pagamento aos empregados de adicional em compensação à agressão que se sujeitavam.

A Normativa presente na NR-15 traz a configuração das mais diversas atividades insalubres e perigosas, entretanto, é notório que se deveria trabalhar em conjunto com políticas de eliminação e redução efetiva dos riscos e exposições.

É evidente que a aplicação da primeira vertente (contenção, neutralização e eliminação) deveria ser de forma primordial, uma vez que traz benefícios muito mais concretos, pela prevenção, e ajuda a garantir os direitos básicos dos trabalhadores, como o direito à saúde e à dignidade humana. Devido a estratégias comerciais e à análise dos custos, constatou-se que a mera retribuição pecuniária seria menos custosa que adotar políticas de reestruturação de uma empresa, sem um amparo estatal efetivo a esse respeito. Entretanto, o pagamento não é a única solução possível. Sebastião Geraldo de Oliveira elenca as três formas principais que as legislações podem adotar para se lidar com agentes agressivos, como a própria política da monetização do risco, a proibição do trabalho e a redução da jornada. ${ }^{7}$

Dentro dessa noção de "benefícios" que os trabalhadores recebem ao se submeterem a condições insalubres e perigosas, há a possibilidade da Aposentadoria Especial, instituída pela Lei 3.807/1960, na qual é possível a aposentaria precoce em determinadas situações. Poderá se

6 BRASIL. Ministério do Trabalho e Emprego. Norma regulamentadora $\mathrm{n}^{\circ}$. 15. Disponível em: <https://goo.gl/ZnbcMm>. Acesso em: 22 fev. 2015.

7 OLIVEIRA, Sebastião Geraldo de. Op. Cit., p. 154-156 
A SUPERAÇÃO DA POLÍTICA DA MONETIZAÇÃO DO RISCO E A INSALUBRIDADE: UMA ÓTICA COMPARATIVA APRESENTADA PELO DIREITO ITALIANO

MARCO ANTÔNIO CÉSAR VILLATORE MIRIAM OLIVIA KNOPIK FERRAZ

aposentar com 15, 20 ou 25 anos de exercício habitual e permanente. Além disso, a renda mensal equivale a $100 \%$ do salário de contribuição e não tem a aplicação do fator previdenciário. O rol apresentado pelo Regulamento da Previdência Social (Decreto $n^{\circ}$. 3.048/1999) é taxativo quanto aos agentes agressores, porém, é exemplificativo quando se trata das atividades listadas, fato que difere da caracterização do adicional de insalubridade, no qual a atividade tem que necessariamente estar presente na listagem do MTE.

Cabe ressaltar que a aposentadoria especial não está diretamente relacionada à percepção do adicional de insalubridade, a exemplo do agente agressor ruído. Em entendimento sumulado, a Turma de Nacional de Uniformização da Jurisprudência dos Juizados Especiais Federais considera " $O$ uso do equipamento de proteção individual, EPI, ainda que elimine a insalubridade, no caso de exposição a ruído, não descaracteriza o tempo de serviço prestado". ${ }^{8}$

Em outro viés brasileiro, encontram-se institutos que colaborariam para uma visão ampla do meio ambiente laboral e a saúde do trabalhador, como as Comissões Internas de Prevenção de Acidentes (CIPA) e o Serviço Especializado em Engenharia de Segurança e Medicina do Trabalho (SESMT). Ambos são responsáveis por elaborar medidas de prevenção de doenças e acidentes no meio ambiente de trabalho.

A CIPA está disciplinada nos arts. 163 a 165 da CLT e regulamentada pela NR-5 do MTE e tem como objetivo proporcionar uma maior participação dos trabalhadores na elaboração e cumprimentos de políticas preventivas. Está relacionada à ideia de cooperação entre empregador e empregados e surgiu principalmente como reflexo das determinações da OIT que elencavam como fator essencial essa integração.

$\mathrm{Na}$ maioria das empresas, a existência desse instituto restou atrelada exclusivamente a uma formalidade, não havendo uma atuação firme e muito menos vinculada aos sindicatos (algo que deveria ser essencial). Já o SESMT foi regulamento pelo art. 162 da CLT e pela NR-4 do MTE, apesar de ter como origem principal a Recomendação $\mathrm{n}^{\circ}$. 112 da OIT: possui como objetivo a promoção e proteção da saúde e integridade do trabalhador. Esta só é obrigatória às "Empresas de grau de risco 4, a partir de 50 empregados; para as empresas de grau de risco 3, a partir de 100 empregador, e para as empresas de grau de risco 1 e 2, a partir de 500 empregados", 9 e,

\footnotetext{
${ }^{8}$ BRASIL. Turma Nacional de Uniformização da Jurisprudência dos Juizados Especiais Federais. Súmula $n^{\circ}$.09. Disponível em: <https://goo.gl/TjFCri>. Acesso em: 25 jan. 2016.

${ }^{9}$ OLIVEIRA, Sebastião Geraldo de. Op. Cit. p. 442.
} 
A SUPERAÇÃO DA POLÍTICA DA MONETIZAÇÃO DO RISCO E A INSALUBRIDADE: UMA ÓTICA COMPARATIVA APRESENTADA PELO DIREITO ITALIANO

MARCO ANTÔNIO CÉSAR VILLATORE MIRIAM OLIVIA KNOPIK FERRAZ

ainda, "em muitas empresas, o SESMT fica reduzido ao papel de medicalização, tratando dos sintomas sem eliminar os agentes agressivos provenientes da atividade exercida". ${ }^{10}$

Há ainda o Programa de Prevenção de Riscos Ambientais (PPRA) e o Programa de Controle Médico de Saúde Ocupacional (PCMSO), que possuem como liame principal a ideia da prevenção. 0 primeiro está previsto na NR-9 do MTE e possui a ideia mais global de antecipação e reconhecimento dos riscos com o objetivo de estabelecer as prioridades e metas de avaliação e controle, de cunho preventivo. ${ }^{11}$

Em paralelo, há o Programa de Controle Médico de Saúde Ocupacional, previsto na NR-7 do MTE, que objetiva também o rastreamento dos riscos, de novas doenças ou danos profissionais. Além disso, a própria norma regulamentadora do Ministério do Trabalho e Emprego determina a realização obrigatória e periódica de exames médicos.

Apesar da extensa normativa apresentada, o que se observa como ponto comum a esses institutos é o problema da efetivação de seus objetivos e funções. $O$ fato de não possuírem a autonomia necessária para ordenar providências e de não haver a real fiscalização de atuação contribui para a estagnação e o cumprimento meramente formal (quando há) de suas obrigações. Assim, observa-se que, em realidade, a prevenção e a extinção dos riscos e doenças ocupacionais continuam em segundo plano, sendo priorizado atualmente a adoção de políticas voltadas à visão da questão somente a posteriori, ou seja, com o único intuito de remunerar a atuação em ambientes insalubres e perigosos.

\section{DO DIREITO COMPARADO: DA ITÁLIA AO BRASIL}

Ambos os países, Brasil e Itália, assemelham-se por possuir construções baseadas em extensas normativas e estruturas similares como a elevação do patamar constitucional, legislações infraconstitucionais e normativas suplementares mais específicas. Ainda, como ressaltado anteriormente, a Itália possui um histórico de preocupação com o Direito do Trabalho, sendo um dos precursores para a autonomia da matéria e, assim, justifica-se e tornase possível a análise comparada de ambos os ordenamentos.

A multiplicidade de normas, em ambos os sistemas, se confrontadas, (aqui considerando toda a extensa normativa sobre a temática da insalubridade e consequentemente a proteção do

\footnotetext{
10 Ibidem, p. 442 e 443.

11 FERNANDES, Fábio. Meio Ambiente Geral e Meio Ambiente do Trabalho: Uma Visão Sistêmica. São Paulo: LTr, 2009, p.23.
} 
A SUPERAÇÃO DA POLÍTICA DA MONETIZAÇÃO DO RISCO E A INSALUBRIDADE: UMA ÓTICA COMPARATIVA APRESENTADA PELO DIREITO ITALIANO

MARCO ANTÔNIO CÉSAR VILLATORE MIRIAM OLIVIA KNOPIK FERRAZ

trabalho e do trabalhador), leva a uma análise minuciosa e de proporções ilimitadas, o que não condiz com o objetivo e possibilidades deste estudo. É diante dessa impossibilidade que se justifica o estudo dos principais institutos acerca da insalubridade e proteção/prevenção, dentro das normativas-base de cada ordenamento: no âmbito brasileiro, a Constituição de 1988, a Consolidação das Leis do Trabalho e a Norma Regulamentadora $\mathrm{n}^{\circ} .15$ do Ministério do Trabalho e Emprego, e, no âmbito Italiano, a Constituição de 1948, o Código Civil de 1942 e o Decreto Legislativo $n^{\circ}$. 81/2008 (Texto único sobre Saúde e Segurança no Trabalho).

Deixa-se para uma futura pesquisa os aprofundamentos minuciosos sobre ambas as legislações, para se voltar ao enfoque principal deste estudo: o comparativo entre a principal normativa acerca da insalubridade, no Brasil e na Itália, com o objetivo de trazer outro viés com base em uma realidade externa para a política da monetização do risco aplicada em predominância no Direito brasileiro.

Além disso, cabe destacar a importância do estudo de ambas as legislações aquém de premissas de superioridade e inferioridade de uma ou de outra, por se tratar de direitos diferentes, com bases e construções históricas diversas, sendo necessário, então, o confronto para o crescimento e como fundamento de inspiração. Paralelamente a isso, não se deve deixar de lado a necessidade de apontar as falhas de ambos os sistemas, demonstrando efetivamente como se materializa cada ordenamento.

\subsection{Constituições}

Ao analisar-se a Constituição Brasileira de 1988 e a Constituição Italiana de 1948, ambas vigentes, atualmente, em seus respectivos ordenamentos, denota-se a positivação em destaque do "Direito à saúde", restando presente no art. 196 da brasileira e no art. 32 da italiana, sendo assim categorizados como direito fundamental. O patamar em que se colocou o direito à saúde em ambos os institutos traz a necessidade de que as normativas posteriores, que puderem de alguma forma afetar esse direito, estarem em consonância a essa elevação de importância e trazerem a possibilidade conjunta de proteção e prevenção.

Esses ideais foram corretamente retratados no próprio art. 196 da Constituição Brasileira, ao tratar de "políticas sociais e econômicas que visem à redução do risco de doenças e de outros agravos, e ao acesso universal e igualitário às ações e serviços para a sua promoção, 
A SUPERAÇÃO DA POLÍTICA DA MONETIZAÇ̃̃O DO RISCO E A INSALUBRIDADE: UMA ÓTICA COMPARATIVA APRESENTADA PELO DIREITO ITALIANO

MARCO ANTÔNIO CÉSAR VILLATORE MIRIAM OLIVIA KNOPIK FERRAZ

proteção e recuperação". ${ }^{12}$ Posteriormente, o art. 70 trata especificamente do direito dos trabalhadores urbanos e rurais, elencando como sendo seus direitos a redução dos riscos provindos do trabalho e a adoção de adicional de remuneração para o labor em condições penosas, insalubres e perigosas.

A Constituição italiana, ao tratar dessa temática, mostra-se um pouco mais abrangente, uma vez que, no art. 38, elenca como direito do trabalhador ter meios adequados quando se constatar um acidente ou doença ocupacional; no art. 41, expressamente elenca que a atividade econômica, em gênero, não pode se fundamentar em detrimento à liberdade, à segurança e à dignidade humana, conceitos que de alguma forma abrangem os ideais de saúde e segurança no trabalho; por fim, o art. 117 retrata a competência concorrente entre o Estado Italiano e as suas regiões (o que poderíamos entender, no âmbito brasileiro, como Estados), sobre matéria de proteção e segurança no trabalho, além do dever do Estado de garantir a uniformização da proteção, em destaque quanto à saúde e à segurança no trabalho. ${ }^{13}$

Da análise comparada das Constituições, tem-se que a brasileira traz a proteção como direito fundamental e posteriormente elenca dois direitos: a redução dos riscos e o adicional. Este último, em nossa realidade atual, serve como limitador das possibilidades protetivas, uma vez que o enfoque dado e a aplicabilidade quanto a essa matéria giram em torno quase exclusivamente desse instituto: da remuneração da saúde/segurança.

Em outro viés, a Constituição Italiana não traz formas de monetização das atividades que envolvem risco à saúde e à segurança, ao contrário, limita-se a traçar linhas iniciais sobre a matéria. O que se destaca é a previsão da competência concorrente já em matéria constitucional e, no mesmo momento, a necessidade de supervisionamento do Estado, na uniformização normativa.

\subsection{Consolidação das Leis do Trabalho brasileira e Código Civil italiano}

A Consolidação das Leis do Trabalho instituída primeiramente pelo Decreto-lei $\mathrm{n}^{\circ} .5 .452$, de 1 o de maio de 1943, e posteriormente revisada por diversas leis, é a principal normativa brasileira a respeito dos direitos dos trabalhadores, em geral, e traz em seu texto disposições

12 BRASIL. Constituição Federal de 1988. Diário Oficial da União. Brasília: Senado Federal, 1988. Disponível em: <https://goo.gl/UYNik9>. Acesso em: 19 jan. 2016.

13 ITÁLIA. Costituzione Della Repubblica Italiana 1948. Disponível em: <https://goo.gl/tSrHsq>. Acesso em: 19 jan. 2016. 
A SUPERAÇÃO DA POLÍTICA DA MONETIZAÇÃO DO RISCO E A INSALUBRIDADE: UMA ÓTICA COMPARATIVA APRESENTADA PELO DIREITO ITALIANO

MARCO ANTÔNIO CÉSAR VILLATORE MIRIAM OLIVIA KNOPIK FERRAZ

específicas sobre a matéria em questão, aqui organizado em sete tópicos: I) Delegação de competência; II) Inspeção; III) Órgãos de segurança e de medicina do trabalho nas empresas; IV) Equipamento de proteção Individual; V) Das medidas preventivas; VI) Insalubridade; VII) Penalidade.

O primeiro tópico é o da delegação de competência, presente no art.155, delegando para os " órgãos de âmbito nacional” a coordenação, fiscalização e demais atos da campanha nacional de prevenção de acidentes. Dentro dessa perspectiva é o Ministério do Trabalho o principal órgão para a elaboração de normativas acerca da temática da saúde e segurança no trabalho, conforme elenca o art. 200 da CLT, competência esta confirmada pela Súmula nº 194 do $\mathrm{STF}^{14}$. Além do enfoque principal no $\mathrm{MT},{ }^{15}$ a CLT traz outras delegações de competência possíveis: no art. 156 para as Delegacias Regionais do Trabalho, ${ }^{16}$ que serão responsáveis por fiscalizar, adotar medidas exigíveis e impor penalidades; o art. 157, traz com relação às próprias empresas, por fim, o art. 158 aos próprios empregados.

O segundo tópico é o da inspeção, presente no art. 160 da CLT, determinando que o estabelecimento comercial de uma empresa só pode funcionar depois de realizada a devida inspeção e sua aprovação, podendo o Superintendente Regional do Trabalho realizar a interdição do estabelecimento, conforme art. $161 \mathrm{da} \mathrm{CLT}$, se for demonstrado em laudo técnico grave ou iminente risco ao trabalhador. Cabe não só a interdição do estabelecimento, em geral, mas também de máquinas, setor de serviço ou equipamento, descrevendo no laudo medidas cabíveis para consertar e evitar futuras lesões.

Essa matéria foi efetivamente regulamentada pela NR-12 do TEM. A norma possibilita ao empregador apresentar Declaração de Instalações que poderá ser aceita pela Superintendência Regional do Trabalho para suprir o objetivo da fiscalização, quando não for possível a realização prévia, o que possibilitou a diversas empresas não terem sua fiscalização presencial efetivada, mas substituída pela declaração de instalações (emitida pela própria empresa).

O terceiro tópico trata dos órgãos de segurança e medicina do trabalho nas empresas. Primeiramente, pelo art.162 da CLT é estipulado que as empresas são obrigadas a manter serviços de segurança e medicina do trabalho dentro de seus estabelecimentos, de acordo com

\footnotetext{
${ }^{14}$ SUPREMO TRIBUNAL FEDERAL. Súmula $\mathrm{n}^{\circ}$. 194. Disponível em: <https://goo.gl/2l4KKi>. Acesso em: 19 mar. 2017.

15 Anteriormente intitulado Ministério do Trabalho e Emprego (MTE), atualmente foi renomeado para Ministério do Trabalho (MT).

${ }^{16}$ Hoje são intituladas Superintendências Regionais do Trabalho.
} 
A SUPERAÇÃO DA POLÍTICA DA MONETIZAÇÃO DO RISCO E A INSALUBRIDADE: UMA ÓTICA COMPARATIVA APRESENTADA PELO DIREITO ITALIANO

MARCO ANTÔNIO CÉSAR VILLATORE MIRIAM OLIVIA KNOPIK FERRAZ

os critérios fixados pelo MTE. Além disso, o art. 163 da CLT dispõe sobre as Comissões Internas de Prevenção de Acidentes (CIPA), instauradas também conforme determinações do MTE.

O quarto tópico trata dos Equipamentos de Proteção Individual, no art.166. Este apenas retrata sua obrigatoriedade e gratuidade. 0 quinto tópico trata das medidas preventivas, que não são todas as presentes no ordenamento brasileiro, apenas há a apresentação de algumas referências.

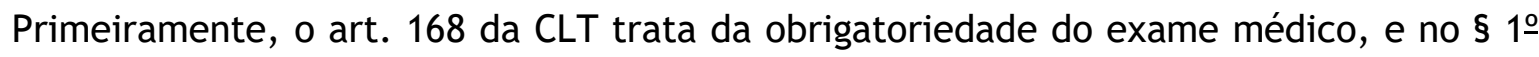
remete-se ao MTE o estabelecimento de quando serão exigíveis exames. 0 art.169 da CLT determina que serão obrigatórias as notificações de doenças profissionais e as decorrentes de condições laborais, em conformidade com disposições do MT.

Após esta parte introdutória trazida pela CLT, há a especificação de algumas atividades como: art.171 da CLT com relação às edificações, os pisos não deverão apresentar saliências; art.175 da CLT trata da necessidade de iluminação adequada; art. 176 da CLT diz respeito ao conforto térmico; a empresa deve proporcionar a ventilação natural, e se esta não estiver em consonância com o conforto térmico, deve promover a ventilação artificial; art. 177 da CLT determina a necessidade da utilização de vestimenta adequada quando o local de trabalho possuir exposição a frio ou calor; art. 178 da CLT elenca que é o MTE que determina os limites de conforto térmico.

O sexto tópico é a compilação dos artigos que tratam especificamente da insalubridade: o art. 189 da CLT elenca os critérios para uma atividade ou operação ser considerada insalubre: esta deve por sua natureza ter condições ou possuir métodos de trabalho, ou expor o empregado a agente nocivos à saúde acimas do limite de tolerância (fixados pela natureza do trabalho ou tempo de exposição). 0 art. 190 da CLT delega a competência para o MTE elaborar os quadros das atividades insalubres e o art. 191 da CLT trata da medida de eliminação ou neutralização, como um gênero que deve conservar o local de trabalho dentro dos limites de tolerância e a necessidade do uso do EPI, sendo responsabilidade das superintendências regionais do trabalho comprovarem a insalubridade e estipular prazos para a eliminação.

$\mathrm{O}$ art. 192 da CLT é o mais lembrado e utilizado. É ele que estipula os percentuais de pagamento a mais para empregados que laboram em condições insalubres de acordo com o grau de exposição em 10\%, 20\% e 40\% sobre o salário mínimo. 0 art. 194 da CLT trata da cessação desse adicional quando eliminado o fator de risco e, por fim, o art. 200 da CLT coloca como competência do MTE realizar a proteção a respeito de substâncias químicas, nocivas, radiações, etc. 
A SUPERAÇÃO DA POLÍTICA DA MONETIZAÇ̃̃O DO RISCO E A INSALUBRIDADE: UMA ÓTICA COMPARATIVA APRESENTADA PELO DIREITO ITALIANO

MARCO ANTÔNIO CÉSAR VILLATORE MIRIAM OLIVIA KNOPIK FERRAZ

O sétimo tópico traz os artigos presentes na CLT que tratam de algumas atividades insalubres específicas (não esgotam o rol de possibilidades). 0 art. 253 da CLT trata da obrigatoriedade de pausas de 20 minutos a cada 1 hora e 40 minutos de exposição para os trabalhos em frigoríficos ou expostos a excesso de frio ou calor; no art. 293 da CLT limita a jornada em minas de até 6 horas. 0 art. 298 da CLT indica que nas minas a cada 3 horas deve haver pausa de 15 minutos, e por fim, de forma mais genérica, o art. 300 da CLT traz a ideia de que a empresa é obrigada a transferir o empregado se houver motivo de saúde/segurança no trabalho.

Paralelamente ao elencado, o Código Civil italiano traz apenas uma disposição sobre a temática estudada. É o art. 2.087, que elenca a obrigatoriedade de o empregador adotar medidas observando a particularidade de cada trabalho, experiência e técnica, necessárias para proteger a integridade física e moral do trabalhador.

A jurisprudência italiana interpreta esse artigo ampliando a sua aplicabilidade e, consequentemente, a sua abrangência, ao elencar que o empregador não deve restringir suas atividades às medidas impostas em leis especiais, devendo adotar outras em observância à evolução tecnológica em si. Cabe ao empregador adotar todas as medidas necessárias para a proteção da saúde. ${ }^{17}$

Além disso, compõem essas medidas protetivas a análise conforme as características objetivas da prestação laboral e as condições subjetivas do trabalhador. ${ }^{18}$ Acrescentam a ideia do exercício de ação de vigilância contínua entre os empregadores aos empregados, para que, sejam observadas as normas de segurança. ${ }^{19}$ Por fim, há parte da jurisprudência italiana que entende que diante do inadimplemento da adoção de medidas de segurança e saúde no trabalho estipuladas pelo artigo em questão, é possível, utilizar a regra do "exceptio non adimplendum contractus", quando diante da inércia do empregador, presente no art.1.460 do Código Civil italiano. $^{20}$

17 OLYMPUS. Amianto: responsabilità datore di lavoro. Disponível em: <https://goo.gl/qcD9pM>. Acesso em: 21 fev. 2017.

18 DIRITTO DEL LAVORO. Illegittimità del licenziamento per trascuratezza dell'obbligo di reperimento di mansioni consone al menomato stato di salute, semprechè sussistenti in azienda. Disponível em: <https: //goo.gl/fqh4FP>. Acesso em: 21 fev. 2017.

19 UNIONCAMERE. Sentenza Corte di Cassazione: 17 febbraio 2003, n. 2.357. Disponível em: <https://goo.gl/jHs35g>. Acesso em: 21 fev. 2017.

${ }^{20}$ ALTALEX. Dipendente può rifiutarsi di lavorare se il datore non adotta le misure di sicurezza. 17 de novembro de 2005. Disponível em: <https://goo.gl/0WxzWT>. Acesso em 21 de fevereiro de 2016. 
A SUPERAÇÃO DA POLÍTICA DA MONETIZAÇÃO DO RISCO E A INSALUBRIDADE: UMA ÓTICA COMPARATIVA APRESENTADA PELO DIREITO ITALIANO

MARCO ANTÔNIO CÉSAR VILLATORE MIRIAM OLIVIA KNOPIK FERRAZ

Sendo assim, denota-se que a CLT apresenta uma complexidade maior com relação à proteção e prevenção do trabalhador, em contrapartida, a legislação italiana coloca no Código Civil de 1942 apenas uma ideia preliminar.

\subsection{Norma Regulamentadora $n^{\circ}$. 15 do MTE brasileira e Decreto $n^{\circ} .81 / 2008$ italiano e legislações esparsas}

Limitou-se a pesquisa aos gêneros trazidos pela NR-15 e pelo Decreto $n^{\circ}$. 81/2008, os que eram abarcados por ambos, ou em cada um deles e os que enfocavam em políticas de prevenção e proteção do trabalho insalubre. Os critérios, mesmo limitados a apenas essas duas normativas, resultaram na distribuição em 25 categorias, aqui selecionadas apenas 14.

Cabe o estudo dessas divisões de modo a traçar qual legislação abarca mais medidas de proteção e prevenção, ressaltando que, quando não presente na NR-15 ou Decreto $n^{\circ} .81 / 2008$, foram procuradas legislações esparsas, de forma apenas a não cometer o erro de apresentar uma lacuna quando não há. Sendo assim, dentro deste estudo há legislações além das duas utilizadas como base.

\subsubsection{Serviços de Prevenção e Proteção}

O mais próximo desse instituto, na realidade brasileira, é o previsto no art. 155 da $\mathrm{CLT}^{21}$, que dispõe incumbir "ao órgão competente sobre matéria de saúde e segurança no trabalho" as funções de coordenar, implementar políticas de prevenção e inclusive a Campanha Nacional de Prevenção de Acidentes.

O Decreto italiano $n^{\circ} .81 / 2008^{22}$ prevê que o serviço de prevenção e proteção será realizado pelo "Datore di Lavoro", que deve organizar esse sistema e tomar como preferência a aplicação dentro da empresa e em segundo plano à unidade produtivas, além da instrução de pessoas ou serviços externos em associação a outro organismo de proteção. Algumas empresas são obrigadas a ter esse serviço especificamente, como termoelétricas, fabricantes de

\footnotetext{
${ }^{21}$ BRASIL. Decreto-lei $n^{\circ} .5 .452,1^{\circ}$. de maio de 1943. Aprova a Consolidação das Leis do Trabalho. Diário Oficial da União. Brasília: 1 maio 1943. Disponível em: <https://goo.gl/0FBcva>. Acesso em 22 fev. 2017. 22 ITÁLIA. Decreto n. 81 de 2008. Texto único de saúde e segurança no trabalho. Disponível em: <https://goo.gl/ZJAfl4>. Acesso em: $15 \mathrm{dez} .2016$.
} 
explosivos, pólvora, munição, indústrias com mais de 200 empregados ou indústrias extrativas com 50 empregados etc.

\subsubsection{Proteção Individual}

Apesar da NR-15 do MTE ser normativa básica a respeito da insalubridade, ela não traz especificações sobre o uso e funcionalidade dos EPI's, tema trazido pela Norma Regulamentadora $\mathrm{n}^{\circ} .6^{23}$ do MTE que dispõe as responsabilidades do empregador em fiscalizar, manter à disposição e consequentemente fornecer o EPI adequado à atividade e à exposição, e traz um rol do que é considerado EPI e quais os padrões de utilização.

Em paralelo, o Decreto $n^{\circ} .81 / 2008{ }^{24}$ traz a normativa geral sobre EPI: elencando como dever do empregador colocar à disposição os equipamentos, principalmente como parte de seus objetivos de redução ao mínimo os riscos laborais. Além disso, traz as determinações do que é EPI e os requisitos para ser considerado um, ampliando as possibilidades, como obrigatoriedade de adequação ao que se pretende prevenir, condições de trabalho e etc. Assim, a diferença entre as legislações é ínfima.

\subsubsection{Construção}

Apesar de comumente elencado com uma atividade suscetível a periculosidade, nas construções também há a possibilidade de exposição a fatores insalubres, como ruídos, poeira, vibrações e etc. A Norma Regulamentadora $n^{\circ} .15^{25}$ do MT não regula o labor em construções, esta atividade é disposta na NR-18 do MTE que determina que: quando há mais de 20 empregados é necessário a realização do Programa de Condições e Meio Ambiente do Trabalho na Indústria da Construção (PCMAT); o que deve conter na área de trabalho; os EPI's; treinamentos e outras disposições específicas. Observa-se que as questões sobre informação e formação e local de trabalho que não tinham disposições gerais anteriormente, são trazidas nesta norma regulamentar.

23 BRASIL. Ministério do Trabalho e Emprego. Norma regulamentadora $\mathrm{n}^{\circ}$. 6. Disponível em: <https://goo.gl/ZnbcMm>. Acesso em: 22 fev. 2017.

24 ITALIA. Decreto n. 81 de 2008. Op. Cit.

${ }^{25}$ BRASIL. Ministério do Trabalho e Emprego. Norma regulamentadora $\mathrm{n}^{\circ}$. 15. Op. Cit. 
A SUPERAÇÃO DA POLÍTICA DA MONETIZAÇ̃̃O DO RISCO E A INSALUBRIDADE: UMA ÓTICA COMPARATIVA APRESENTADA PELO DIREITO ITALIANO

MARCO ANTÔNIO CÉSAR VILLATORE MIRIAM OLIVIA KNOPIK FERRAZ

O Decreto italiano $\mathrm{n}^{\circ} .81 / 2008^{26}$ traz disposições sobre construção temporária ou móvel, prevendo a obrigatoriedade da elaboração de um plano de segurança e coordenação e uma cartilha de instruções de prevenção e proteção dos riscos, este elaborado em conformidade com as peculiaridades de cada trabalhador. Destaca-se a figura do "Datore di Lavoro" como garantidor do local de trabalho, e este deve realizar o mapeamento dos serviços. Assim, o enfoque da normativa italiana se mantém em seus ideais, e a norma brasileira se apresentar satisfatoriamente abrangente.

\subsubsection{Ruído}

Elencado como primeiro agente físico dentro da normativa italiana, este não possui referência na NR-15 do MT, porém é previsto em 4 decretos, dos anos de 2006 e 2007: DecretoLei $n^{\circ}$. 9/2007 e $n^{\circ} .278 / 2007$, o primeiro aprova o Regulamento Geral do Ruído e o segundo altera este. O Decreto-Lei $n^{\circ}$. 221/2006 traz as emissões sonoras para o ambiente, e dos equipamentos utilizados no exterior; e por fim, o que traz maior relevância a este estudo, o Decreto-Lei $n^{\circ}$. 182/2006 ${ }^{27}$ traz em seu corpo prescrições de saúde e segurança.

Do estudo desse decreto denota-se que este possui uma complexidade maior que a própria NR-15, a sua construção normativa é mais detalhada e completa, além da própria previsão acerca de políticas preventivas e protetivas ser bem mais abrangente que a regulamentação do MT. Dentre o presente na norma, destacam-se a previsão dos princípios norteadores da avaliação dos riscos, a própria avaliação realizada por meio de análise subjetiva, informação e formação dos trabalhadores e a ideia de vigilância da saúde efetuada pelo próprio empregador.

Já o Decreto italiano $\mathrm{n}^{\circ}$. $81 / 2008^{28}$, como normativa básica apresenta disposições expressas sobre o agente ruído, seguindo os parâmetros dessa regulamentação preventiva e protetiva, sendo assim, trata da valoração dos riscos, políticas de prevenção, e como inovação e diferente do que normalmente se abrange nessas questões, há além da previsão da regulamentação da intensidade de exposição, o horário apropriado para labor e o suficiente

26 ITALIA. Decreto n. 81 de 2008. Op. Cit.

27 BRASIL. Decreto- Lei $n^{\circ}$. 182, de 06 de setembro de 2006. Transpõe para a ordem jurídica interna a Directiva n. ${ }^{\circ} 2003 / 10 / C E$, do Parlamento Europeu e do Conselho, de 6 de Fevereiro, relativa às prescrições mínimas de segurança e de saúde em matéria de exposição dos trabalhadores aos riscos devidos aos agentes físicos (ruído). Diário Oficial da União. Brasília: 6 set. 2006. Disponível em: <https://goo.gl/Twlg9s>. Acesso em 23 de fevereiro de 2017.

${ }^{28}$ ITALIA. Decreto ${ }^{\circ}$. 81. Op. Cit. 
A SUPERAÇÃO DA POLÍTICA DA MONETIZAÇ̃̃O DO RISCO E A INSALUBRIDADE: UMA ÓTICA COMPARATIVA APRESENTADA PELO DIREITO ITALIANO

MARCO ANTÔNIO CÉSAR VILLATORE MIRIAM OLIVIA KNOPIK FERRAZ

período de repouso, há a previsão da limitação de jornada, algo que é elencado como umas das principais soluções para a tendência da monetização do risco.

Verifica-se que a legislação brasileira avança quanto a esse fator e destaca-se a inovação da legislação italiana, apesar de limitada a fatores de risco específicos e não como determinação geral, quanto a necessidade de observância da possibilidade da redução da jornada do trabalhador que labora em exposição a agentes insalubres.

\subsubsection{Vibração}

$\mathrm{O}$ agente insalubre de vibração está presente na normativa brasileira na NR-15 do $\mathrm{MT}^{29}$ em seu anexo $n^{\circ} .7$ apenas quanto a sua graduação e o entendimento de que a exposição sem proteção é considerada atividade insalubre. Além disso, o decreto Lei $n^{\circ}$. 46/2006 ${ }^{30}$ traz as prescrições protetivas e preventivas mínimas seguindo o padrão normativo com relação ao ruído (princípios norteadores da avaliação dos riscos, a própria avaliação realizada por meio de análise subjetiva, informação e formação dos trabalhadores, a ideia de vigilância da saúde efetuada pelo próprio empregador).

A legislação italiana mantém o padrão trazido pelo Decreto no $81 / 2008^{31}$. Assim, elenca limites de prevenção, valoração dos riscos, busca de métodos alternativos de realização do labor que eliminem ou limitem a exposição etc.

\subsubsection{Eletromagnético}

Na legislação brasileira, esse fator está previsto na Lei no $11.934 / 2009^{32}$, que traz apenas limites gerais de exposição humana a campos elétricos, magnéticos e eletromagnéticos.

\footnotetext{
${ }^{29}$ BRASIL. Ministério do Trabalho e Emprego. Norma regulamentadora $\mathrm{n}^{\circ}$. 15. Op. Cit.

30 BRASIL. Decreto Lei $n^{\circ}$. 46, de 24 de fevereiro de 2006. Transpõe para a ordem jurídica nacional a Directiva n. ${ }^{\circ}$ 2002/44/CE, do Parlamento Europeu e do Conselho, de 25 de Junho, relativa às prescrições mínimas de protecção da saúde e segurança dos trabalhadores em caso de exposição aos riscos devidos a agentes físicos (vibrações). Diário Oficial da União. Brasília: 24 fev. 2008. Disponível em: <https://goo.gl/yAJOuN>. Acesso em: 23 fev. 2017

31 ITALIA. Decreto ${ }^{\circ}$. 81. Op. Cit.

32 BRASIL. Lei $n^{\circ}$. 11.934, de 05 de maio de 2009. Dispõe sobre limites à exposição humana a campos elétricos, magnéticos e eletromagnéticos; altera a Lei no 4.771, de 15 de setembro de 1965; e dá outras providências. Diário Oficial da União. Brasília: 5 maio 2009. Disponível em: <https://goo.gl/KTLjFA>. Acesso em: 23 fev. 2017.
} 
A SUPERAÇÃO DA POLÍTICA DA MONETIZAÇ̃̃O DO RISCO E A INSALUBRIDADE: UMA ÓTICA COMPARATIVA APRESENTADA PELO DIREITO ITALIANO

MARCO ANTÔNIO CÉSAR VILLATORE MIRIAM OLIVIA KNOPIK FERRAZ

Segundo a Associação Nacional de Medicina do Trabalho (ANAMT) ${ }^{33}$, a legislação brasileira não abrange limites de exposição para campos elétricos, magnéticos e eletromagnéticos; estes são trazidos pela Associação Nacional de Telecomunicações (ANATEL) que adotou os elencados pela Comissão Internacional para a Proteção Contra a Radiação Não ionizante (ICNIRP), com o objetivo do controle das emissões de radiofrequência provindas de estações transmissoras de telecomunicações.

O Decreto $n^{\circ}$. $81 / 2008^{34}$ apresenta os padrões de ações protetivas e preventivas italianas elencados para os outros fatores, não trazendo inovações quanto a essa matéria. Sendo assim, denota-se que a legislação brasileira é completamente omissa quanto a essa temática e, apesar de existirem dentro de normativas expedidas por Agencias Regulamentadoras e pela Comissão Internacional, estas tratam de uma forma global sobre a exposição a esses agentes e não especificamente sobre o trabalho nessas condições.

\subsubsection{Radiações}

O fator radiação é abrangido de formas diferentes por cada uma das legislações. Enquanto a brasileira trata especificamente das "radiações ionizantes ${ }^{35}$ ", a italiana trata das “radiações óticas artificiais", que são uma espécie de radiação presente no gênero "radiações não ionizantes". Desta forma, em ambas as legislações diversos tipos de radiações não são analisados.

A normativa brasileira está presente na NR-15 do $\mathrm{MTE}^{36}$, no anexo $\mathrm{n}^{\circ}$. 7, que determina as operações que expõem a radiações ionizantes, de ausente proteção, sendo consideradas insalubres. Essa normativa se completa pelo Decreto Lei $n^{\circ}$. $180 / 2002^{37}$ que estabelece as formas

33 ASSOCIAÇÃO NACIONAL DE MEDICINA DO TRABALHO. Legislação. Disponível em: <https://goo.gl/ONH1tX>. Acesso em: 23 fev. 2016.

34 ITALIA. Decreto n. 81. Op. Cit.

${ }^{35}$ A portaria $n^{\circ}$. 3.393/1987 do MTE classificou a radiação ionizante como fator periculoso. Entretanto esse é um dos fatores em que há discussão acerca de sua classificação por oferecer diferentes riscos dependendo da exposição. Sobre essa temática: BRASIL, Secretaria da Saúde. Governo do Estado do Paraná. Sanitaria - Serviços - Radiação lonizante - Efeitos Biológicos da Radiação. Disponível em: <https://goo.gl/mn5S2C >. Acesso em: 22 fev. 2016.

${ }^{36}$ BRASIL. Ministério do Trabalho e Emprego. Norma regulamentadora $\mathrm{n}^{\circ}$. 15. Op. Cit.

${ }^{37}$ BRASIL. Decreto-Lei $n^{\circ}$. 180, de 08 de agosto de 2002. estabelece as normas relativas à protecção da saúde das pessoas contra os perigos resultantes das radiações ionizantes em exposições radiológicas médicas e transpõe para a ordem jurídica interna a Directiva n.o 97/43/ EURATOM, do Conselho, de 30 de Junho, que revoga a Directiva n.o 84/466/EURATOM. Diário Oficial da União. Brasília: 8 ago. 2002. Disponível em: <https://goo.gl/hSwEll>. Acesso em: 23 fev. 2017. 
A SUPERAÇÃO DA POLÍTICA DA MONETIZAÇÃO DO RISCO E A INSALUBRIDADE: UMA ÓTICA COMPARATIVA APRESENTADA PELO DIREITO ITALIANO

MARCO ANTÔNIO CÉSAR VILLATORE MIRIAM OLIVIA KNOPIK FERRAZ

de proteção a respeito desse fator de maneira sucinta e não tão aprofundada quanto a normativa acerca da vibração e ruído.

Na normativa italiana, destaca-se a posição do "Datore di Lavoro" que deve utilizar dos parâmetros estipulados pela Comissão Eletrotecnica Internacional quando se tratar de radiações laser, e apresenta inovação ao tratar da limitação da jornada.

\subsubsection{Agentes Cancerígenos}

A NR-15 do $M T^{38}$ não dispõe especificamente sobre esses fatores, restando para o Decreto-Lei $n^{\circ}$. 301/2000 trazer disposições sobre agentes cancerígenos ou mutagênicos. Denotase da pesquisa, que há um estudo direcionado e complexo sobre o tema, seguindo os padrões dos decretos brasileiros que tratam sobre agentes insalubres: prevê políticas de formação e informação, medidas de higiene, valoração dos riscos e o foco direcionado na substituição ou limitação da utilização desses agentes.

A normativa italiana, presente no Decreto $n^{\circ} .81 / 2008^{39}$, segue, novamente, o padrão de suas estipulações sobre a matéria, inovando quanto à necessidade de justificação para a utilização desses agentes, além do registro de exposição com dados valorativos e agentes e uma cópia deve ser endereçada para o ISPESL.

\subsubsection{Agentes biológicos}

A NR-15 do MT não dispõe especificamente sobre esses fatores, restando para as normativas a seguir prever a regulamentação: Decreto-Lei $n^{\circ}$. 2/200140 regula a utilização confinada de microrganismos geneticamente modificados; a Portaria $n^{\circ}$. 1036/1998 ${ }^{41}$ prevê a lista dos agentes biológicos classificados para efeitos da prevenção de riscos profissionais; a

\footnotetext{
${ }^{38}$ BRASIL. Ministério do Trabalho e Emprego. Norma regulamentadora $\mathrm{n}^{\circ}$. 15. Op. Cit.

39 ITALIA. Decreto ${ }^{\circ}$. 81. Op. Cit.

${ }^{40}$ BRASIL. Decreto Lei $n^{\circ}$. 2, de 04 de janeiro de 2001. Regula a utilização confinada de microrganismos geneticamente modificados, transpondo para a ordem jurídica interna a Directiva n. ${ }^{\circ} 98 / 81 / \mathrm{CE}$, do Conselho, de 26 de Outubro, que altera a Directiva n. ${ }^{\circ}$ 90/219/CEE, do Conselho, de 23 de Abril. Diário Oficial da União. Brasília: 4 jan. 2001. Disponível em: < https://goo.gl/GJKSwy>. Acesso em: 23 fev. 2017.

41 BRASIL. Portaria $\mathrm{n}^{\circ}$. 1.036, de 15 de novembro de 2016. Altera a lista dos agentes biológicos classificados para efeitos de prevenção de riscos profissionais, aprovada pela Portaria $n^{\circ} 405 / 98$, de 11 de Julho. Diário Oficial da União. Brasília: 15 nov. 2016. Disponível em: <https://goo.gl/8QZkrk>. Acesso em 23 de fevereiro de 2017.
} 
A SUPERAÇÃO DA POLÍTICA DA MONETIZAÇ̃̃O DO RISCO E A INSALUBRIDADE: UMA ÓTICA COMPARATIVA APRESENTADA PELO DIREITO ITALIANO

MARCO ANTÔNIO CÉSAR VILLATORE MIRIAM OLIVIA KNOPIK FERRAZ

Portaria $n^{\circ}$. 405/1998 ${ }^{42}$ aprova a classificação dos agentes biológicos; o Decreto-Lei ${ }^{\circ}$. 84/1997 traz disposições sobre a proteção da segurança e saúde dos trabalhadores contra os riscos resultantes da exposição a agentes biológicos durante o trabalho.

A normativa italiana ${ }^{44}$ segue, novamente, o padrão de suas estipulações sobre a matéria, diferenciando apenas quanto a separação dos agentes biológicos em grupos, de acordo com a seu risco à saúde e possíveis adversidades que pode causar. Além disso, o Ministério do Trabalho Saúde e Política Social deve comunicar o órgão responsável pela vigilância quando houver alteração na utilização de agente biológico classificado no grupo 4 (que podem causar doença grave ou oferecer risco grave de propagação na comunidade).

\subsubsection{Local úmido}

Essa condição de trabalho é prevista, no Brasil na NR-15 em seu anexo 10, de forma ampla, abrangendo as condições de trabalho em locais alagados, encharcados e com umidade excessiva, todos considerados insalubres.

Em contrapartida, o Decreto $n^{\circ}$. 81/2008 traz normativas gerais sobre "condições climáticas no local de trabalho", entretanto, essas condições laborais podem ser abrangidas pelos ideais de agente físicos, o que tange à categoria de "microclima".

\subsubsection{Trabalho submerso}

Em ambos os sistemas estão as disposições acerca do trabalho submerso. No sistema brasileiro, está elencado expressamente na NR-15 do MTE, trazendo em seu corpo responsabilidades do empregador em curso de formação, exigência de atestados, garantir aplicação do programa médico; destaca a obrigatoriedade da realização de exames admissionais e periódico.

\footnotetext{
42 BRASIL. Decreto $n^{\circ} .405$, de 11 de julho de 1998. Aprova a classificação dos agentes biológicos. Diário Oficial da União. Brasília: 11 jul. 1998. Disponível em: < https://goo.gl/7bN2ut> Acesso em 23 fev. 2017.

${ }^{43}$ BRASIL. Decreto ${ }^{\circ}$. 84, 16 de abril de 1997. Transpõe para a ordem jurídica interna as Directivas do Conselho n..$^{\circ}$ 90/679/CEE, de 26 de Novembro, e 93/88/CEE, de 12 de Outubro, e a Directiva n. ${ }^{\circ}$ 95/30/CE, da Comissão, de 30 de Junho, relativas à protecção da segurança e saúde dos trabalhadores contra os riscos resultantes da exposição a agentes biológicos durante o trabalho. Diário Oficial da União. Brasília: 16 abr. 1997. Disponível em: <https://goo.gl/NUwQ6r>. Acesso em 23 de fevereiro de 2017.

44 ITALIA. Decreto nº. 81. Op. Cit.
} 
A SUPERAČ̃̃ DA POLÍTICA DA MONETIZAÇÃO DO RISCO E A INSALUBRIDADE: UMA ÓTICA COMPARATIVA APRESENTADA PELO DIREITO ITALIANO

MARCO ANTÔNIO CÉSAR VILLATORE MIRIAM OLIVIA KNOPIK FERRAZ

No sistema italiano, está previsto em norma técnica (a UNI 11366 ${ }^{45}$ ) com especificações mais amplas acerca desse agente, prevendo requisitos, graus de submersão, curso de formação e informação, etc.

\subsubsection{Trabalho sob ar comprimido}

Na Norma Regulamentadora $n^{\circ} .15$ do MTE há disposições voltadas à orientação dos riscos decorrentes dessa atividade, precauções, educação audiovisual e o enfoque na supervisão médica no trabalho.

No sistema italiano, esse agente é previsto no Decreto $n^{\circ} .321$, de 20 de março de $1956^{46}$, e prevê, além do elencado na normativa brasileira, ideais desde construção do local de trabalho nessas condições, a limites de exposição, intervalos, limites etários, etc.

\subsubsection{Baixas temperaturas}

A NR-15 do MTE apenas dispõe que o labor executado em câmeras frigoríficas (ou locais similares), sem a devida proteção, é considerado insalubre. Cabe ressalvar o disposto na CLT, acerca do conforto térmico, elencado anteriormente. Em contrapartida, o Decreto italiano $\mathrm{n}^{\circ}$. 81/2008 em seu anexo IV traz normativas gerais acerca das condições climáticas, no local de trabalho.

O próprio entendimento de "microclima" do tópico de agentes físicos abrange de alguma forma essa matéria. Por fim, cabe ressaltar a existência das normas técnicas UNI EM 27243 e 12515 que tratam sobre a valoração do estresse técnico e a interpretação desses valores, no caso de labor em altas temperaturas, e que de certa forma pode ser utilizado por analogia. Denota-se que ambas as legislações não trazem especificações complexas sobre a matéria.

\subsubsection{Anexos específicos}

45 ITÁLIA Norma Técnica UNI 11.366. Disponível em:<https://goo.gl/ArAZV9>. Acesso em 20 fev. 2017. ${ }^{46}$ ITÁLIA. Decreto nº 321 de 1956. Disponível em:<https://goo.gl/RfguzE>. Acesso em 20 fev. 2017. 
A SUPERAÇÃO DA POLÍTICA DA MONETIZAÇÃO DO RISCO E A INSALUBRIDADE: UMA ÓTICA COMPARATIVA APRESENTADA PELO DIREITO ITALIANO

MARCO ANTÔNIO CÉSAR VILLATORE MIRIAM OLIVIA KNOPIK FERRAZ

Cabe ressalvar que os tópicos acima mencionados abrangem toda a temática básica prevista na NR-15 e no Decreto $n^{\circ}$. 81/2008. Quando não previstos em um ou em outro, foram apresentadas legislações esparsas para a completude do estudo e a não apresentação como lacuna, se havia correspondência nos respectivos ordenamentos.

Além desta extensa explanação, há diversos outros agentes e especificidades sobre a matéria que são abrangidos em ambas as legislações, quando analisado todo o conjunto em torno da insalubridade. Cabe ressaltar ainda que dentro do próprio Decreto $n^{\circ}$. 81/2008 há 51 anexos que tratam de diversas atividades e fatores em específico. Apesar dessa diversidade de previsões, é possível, com o estudo realizado, traçar os principais fatores e tendências de cada sistema e, assim, demonstrar as similitudes e o que poderia ser tomado como inspiração para o sistema brasileiro.

\section{NECESSIDADE DE REFORMULAÇÃO}

Do estudo realizado, apreende-se que, se forem comparados exclusivamente a NR-15 do MTE e o Decreto Italiano $n^{\circ} .81 / 2008$, ambas legislações bases para este estudo, conclui-se pela grande maioria dos critérios comparativos (abstraídos de ambas as normas), que o decreto italiano possui uma completude e complexidade maior que a normativa brasileira em questão.

Das principais características estudadas, a legislação brasileira, sobre questões de saúde e insalubridade laboral, é demasiadamente esparsa, principalmente se comparada à italiana, na qual o decreto básico é considerado uma compilação das normas a esse respeito. Sendo assim, abstrai-se desta pesquisa que a normativa básica italiana é mais completa e, apesar de possuir lacunas, abrange em um mesmo instrumento diversos fatores de risco, e dentro deles, apresenta aprofundamentos que a norma regulamentadora básica brasileira não faz.

Quanto às previsões protetivas, o Brasil apresenta uma visão menos adequada aos ideais de prevenção que tanto se elenca como essencial. A NR-15 do MT, primeiramente, possui uma limitação quanto aos fatores de risco que elenca em seu corpo. Por não estarem presentes nessa normativa, não resultam em indenizações ou políticas preventivas, e ainda possui valores de limite de tolerância muito maiores do que o recomendado internacionalmente, afinal, não há atualização expressiva há $38 \operatorname{anos}^{47}$. A Associação Brasileira de Higienistas Ocupacionais relata

47 BITTAR, César; LOZOVEY, João Carlos do Amaral; ITANI, Alice; KULAY, Luiz Alexandre. A saúde do trabalhador: considerações sobre a gestão diante dos riscos e limites de tolerância à exposição da saúde. 
A SUPERAÇÃO DA POLÍTICA DA MONETIZAÇ̃̃O DO RISCO E A INSALUBRIDADE: UMA ÓTICA COMPARATIVA APRESENTADA PELO DIREITO ITALIANO

MARCO ANTÔNIO CÉSAR VILLATORE MIRIAM OLIVIA KNOPIK FERRAZ

essa problemática, discutida no Seminário de Pós-Graduação da FUNDACENTRO, apontando que 52\% dos valores dos Limites de Tolerância estão desatualizados perante as recomendações da $A C G I H \circledast$, e há fatores que extrapolam os limites em até 156 vezes, como no caso do cloreto de vinila, dentre outros. ${ }^{48}$

Em atenção a essa realidade, no V Congresso Brasileiro de Higiene Ocupacional e XVII Encontro Brasileiro de Higienistas Ocupacionais, da Associação Brasileira de Higiene Ocupacional $(\mathrm{ABHO})$, membros da diretoria deste último e com uma das autoridades signatárias, o presidente da Associação Nacional de Medicina do Trabalho, proferiram moção a respeito da NR-15, com o objetivo de atualizá-la aos novos critérios e padrões internacionais para o Ministério do Trabalho ${ }^{49}$, além de a própria revolução tecnológica provocar o contínuo processo de atualização e modernização. ${ }^{50}$

Além disso, a maioria dos agentes insalubres que esta normativa prevê limita-se à previsão de graus de insalubridade com o objetivo de auferir o percentual de pagamento ${ }^{51}$ a ser realizado e, quando muito, traz determinações mínimas acerca da prevenção e da proteção, como, por exemplo, somente no caso dos agentes químicos, aprofunda-se na questão de avaliação de concentração, ação de vigilância, adequação da proteção individual, etc.

Em paralelo, observa-se o extenso aprofundamento trazido pelos decretos dos anos de 2006 e 2007, acerca dos fatores insalubres de ruído, radiações, agentes cancerígenos e agentes biológicos. 0 destaque dos decretos produzidos sobre o labor exposto a esses fatores está no aprofundamento realizado. Em cada um se seguia o padrão de estrutura não visto na NR-15.

Da análise do Decreto italiano $\mathrm{n}^{\circ} .81 / 2008$, abstrai-se como característica principal que ele abrange muitos agentes passíveis de causar dano ou oferecer risco e segue uma linha organizacional de proteção: primeiramente elenca as obrigações e determinações gerais aplicáveis a qualquer fato, e, posteriormente, da análise individual de cada um verifica-se a necessidade do "Datore di Lavoro" valorar o risco, adaptar as condições de trabalho para os

Revista de Saúde, Meio Ambiente e Sustentabilidade, São Paulo. Volume 6, nº. 3, 2011. Disponível em: < https://goo.gl/HGMCVD>. Acesso em: 26 fev. 2016.

48 ASSOCIAÇÃO BRASILEIRA DE HIGIENISTAS OCUPACIONAIS. Seminário da Pós-Graduação da FUNDACENTRO aborda a NR-15. Disponível em:<https://goo.gl/6YglQy>. Acesso em: 25 fev. 2017.

49 ASSOCIAÇÃO NACIONAL DE MEDICINA DO TRABALHO. Entidades enviam moção sobre a NR-15 ao Ministério do Trabalho. Disponível em: < https://goo.gl/U1Cpl6>. Acesso em 25 fev. 2017.

${ }^{50}$ GONÇALVES, Edwar Abreu. Manual de segurança e saúde no trabalho. 3. ed., São Paulo: LTr, 2006.

${ }^{51}$ SIMONIN, Camille. Médecine Du Travail. 1956, apud NOGUEIRA, Diogo Pupo. A insalubridade na empresa e o médico do trabalho. Revista Brasileira de Saúde Ocupacional, São Paulo, v. 12, n. 45, p. 40-51, jan/mar.1948. 
A SUPERAÇÃO DA POLÍTICA DA MONETIZAÇ̃̃O DO RISCO E A INSALUBRIDADE: UMA ÓTICA COMPARATIVA APRESENTADA PELO DIREITO ITALIANO

MARCO ANTÔNIO CÉSAR VILLATORE MIRIAM OLIVIA KNOPIK FERRAZ

empregados, a prevenção através de políticas de informação e formação, EPI, eliminação ou diminuição da utilização desse fator, etc.

Mesmo possuindo, no início do decreto a parte geral, as obrigações consideradas padrões e mínimas são repetidas separadamente em cada fator insalubre, o que torna a leitura exaustiva e, sob o aspecto da facilidade de informação e praticidade, acaba prejudicando as partes da relação de trabalho. Cabe ressaltar que o decreto também é complementado por outras, leis e normas técnicas. Nos casos previstos nos gêneros elencados somente restavam ausentes o labor submerso e sob ar comprimido.

Com isso, cabe destacar que, do estudo comparativo de ambos os ordenamentos sobre essa temática, vislumbram-se dois problemas que trabalham em conjunto: a da dispersão das normas e a da aplicabilidade destas.

A questão da dispersão das normas é evidente quando estudado o ordenamento brasileiro e italiano, embora em proporções diversas. Diversos fatores como ruído, agentes cancerígenos, eletromagnético, agentes biológicos, etc., estão previstos em normas esparsas na NR-15, e o mesmo ocorre com a normativa italiana, nos fatores de trabalho submerso e sob ar comprimido. Para ambos os sistemas, essa multiplicidade de normas é prejudicial, uma vez que dificulta o acesso à esta informação, principalmente das empresas, que deverão adotar as medidas preventivas e protetivas ${ }^{52}$ e estar atentas aos limites de exposição.

Apesar de a normativa brasileira possuir, não de forma tão completa como a italiana, alguns direcionamentos protetivos e preventivos, estes não são aplicados substancialmente nos nossos sistemas. A política da monetização do risco não é pautada pela ausência de normas, mas, principalmente pela ausência da aplicabilidade e efetividade delas, ressalvando a necessidade de atualização da NR-15 e de completude acerca dos ideais internacionais de proteção e prevenção. ${ }^{53}$ Apesar de a normativa italiana se mostrar mais concisa e estruturada que a brasileira, esta também é fulminada por essa problemática.

A doutrina brasileira ressalva a inaplicabilidade das normas mais complexas quando existe a possibilidade de aplicar o básico. A utilização do EPI deveria ser a última alternativa,

\footnotetext{
52 ALMEIDA, Raquel. Aplicação do Fator Acidentário de Prevenção: entre a intervenção estatal e a livre concorrência e iniciativa. Revista de Direito da Administração Pública, vol. I, nº. I, 2012. Disponível em:< http://www.redap.uff.br/index.php/redap/ article/download/6/7>. Acesso em: 16 maio 2016.

${ }^{53}$ DELLA ROSA, Henrique V.; SIQUEIRA, Maria Elisa Pereira Bastos; COLACIOPPO, Sérgio. Monitoramento Ambiental e Biológico. Apud OGA, Seizi; CAMARGO, Márcia Maria de Almeida; BATISTUZZO, José Antonio de Oliveira. Fundamentos de Toxicologia. São Paulo: Atheneu, 2008.
} 
A SUPERAÇÃO DA POLÍTICA DA MONETIZAÇ̃̃O DO RISCO E A INSALUBRIDADE: UMA ÓTICA COMPARATIVA APRESENTADA PELO DIREITO ITALIANO

MARCO ANTÔNIO CÉSAR VILLATORE MIRIAM OLIVIA KNOPIK FERRAZ

por ser eminentemente para proteção, após outras alternativas que possuem enfoque em prevenção. ${ }^{54}$

A doutrina italiana põe foco no problema das inúmeras normativas presentes em seu ordenamento em contraposição à ausência de efetividade, entendendo que "a solução do problema não reside na edição de novas normas, mas, em se conferir verdadeira efetividade àquelas em vigor". ${ }^{55}$ Ainda, "embora se trate de normas avançadas e bem-elaboradas, é o país onde elas são menos respeitadas e gozam de menor efetividade. ${ }^{56}$

A solução para a política da monetização do risco pode ser vista de duas formas: a possibilidade da redução da jornada, quando houver a exposição a agentes insalubres e, em segundo plano, chegar à proteção global presente no sistema italiano, adotando uma visão de prevenção, proteção e fiscalização. Além disso, como elenca Sebastião Geraldo de Oliveira, o ideal seria a adoção do modelo elencado na Hungria (Código de Trabalho de 1992) e no Irã, países nos quais, além da instituição da duração de 6 horas da jornada, há a proibição do trabalho extraordinário, quando se tratar de jornada insalubre. ${ }^{57}$

Cabe ressalvar que mesmo formando um sistema normativo perfeito, abrangendo todas as proteção e prevenções provindas dos melhores ordenamentos, de nada adiantaria se não houvesse a aplicabilidade e a consequente eficácia das normas e políticas de prevenção. É necessária, além de reformas normativas, a realização da mudança de cultura, do imediatismo do pagamento adicional para a ideia de preservação da saúde e segurança no trabalho. Isso só será possível com ações conjuntas da sociedade e não somente a onerosidade do empregador, ou a facilitação em detrimento da saúde do empregado.

\footnotetext{
${ }^{54}$ OLIVEIRA, Sebastião Geraldo de. Op. Cit, p. 164 e 165.

55 SANLORENZO, Rita. La tutela della legalità e della sicurezza sul luogo di lavoro nel sistema attuale. Palestra proferida no Seminário "Sicurezza sul lavoro: il sistema attuale e le prospettive di riforma", realizado no Palazzo Gazzoli, em Terni (Itália), em 16/06/2007. In: PORTO, Lorena Vasconcelos. A reforma legislativa em matéria de saúde e segurança no trabalho no direito italiano: uma análise crítica. Revista Brasileira de Estudos Políticos, v. 99, 2009. Disponível em :< https://goo.gl/g966sW>. Acesso em 25 fev. 2017.

56 DEIDDA, Beniamino. Le prospettive di riforma. Il progetto del Testo Unico. Palestra proferida no Seminário "Sicurezza sul lavoro: il sistema attuale e le prospettive di riforma", realizado no Palazzo Gazzoli, em Terni (Itália), em 16/06/2007.In: PORTO, Lorena Vasconcelos. A reforma legislativa em matéria de saúde e segurança no trabalho no direito italiano: uma análise crítica. Revista Brasileira de Estudos Políticos, v. 99, 2009. Disponível em :< https://goo.gl/g966sW>. Acesso em 25 fev. 2017.

${ }^{57}$ OLIVEIRA, Sebastião Geraldo de. Op. Cit.
} 
A SUPERAÇÃO DA POLÍTICA DA MONETIZAÇÃO DO RISCO E A INSALUBRIDADE: UMA ÓTICA COMPARATIVA APRESENTADA PELO DIREITO ITALIANO

MARCO ANTÔNIO CÉSAR VILLATORE MIRIAM OLIVIA KNOPIK FERRAZ

Uma das medidas que a doutrina ${ }^{58}$ elenca é a substituição do adicional, que onera o empregador e permite que o trabalhador venda sua saúde, para a promoção de programas estatais voltados a benefícios para as empresas que investirem em prevenção. Assim, o sistema traria a inversão da lógica: o empregador veria como algo positivo a implementação de medidas preventivas e até o estudo para aperfeiçoamento destas e, como consequência, o empregado não abriria mão de sua saúde.

Do estudo global apresentado, entende-se a necessidade: do fomento à criação de novas bases pela unificação das normativas; o enfoque na atualização destas, conforme parâmetros internacionais e necessidades internas; a mudança de foco, como o necessário direcionamento para a prevenção do risco e não a monetização deste. Como patamar inicial, na redução da jornada, proibição do labor extraordinário e, como reflexo, a substituição da política da monetização do risco por uma política de prevenção e proteção da saúde, esta interligada às necessidades dos trabalhadores e em consonância com as possibilidades do empregador, com políticas estatais direcionadas.

\section{CONCLUSÃO}

A política da monetização do risco, tão enraizada no sistema normativo brasileiro, limita desde o princípio a aplicação das mínimas previsões protetivas que já são previstas em lei. Diante da ausência de previsões, na NR-15, observa-se que foram: promovidos decretos apartados e a consequente ausência de previsão do adicional; os limites apresentados estão completamente defasados e, em muitos casos, apresentam-se acima dos padrões internacionais, ou seja, a empresa, mesmo que seguisse a regra, estaria expondo os seus trabalhadores a doenças ocupacionais.

A Itália, como um dos países precursores no desenvolvimento do Direito do Trabalho, destaca-se pela predominância de uma política prevencionista, de maior controle, especificidade e com constantes atualizações. Ambos os países, Brasil e Itália, assemelham-se por possuírem construções baseadas em extensas normativas e estruturas similares com a elevação do patamar constitucional, legislações infraconstitucionais e normativas suplementares mais específicas, e, assim, a análise comparada de ambos os ordenamentos se torna possível.

${ }^{58}$ CAMPAGNOLI, Adriana de Fátima Pilatti Ferreira. MANDALOZZO, Silvana Souza Netto. Uma (re)leitura do art. $7^{\circ}$., XXIII, da Constituição da República: Possíveis Alternativas para a Monetização do Risco com enfoque em atividades Insalubres. Disponível em: <https://goo.gl/fRg0D2>. Acesso em 10 jan. 2017. 
A SUPERAÇÃO DA POLÍTICA DA MONETIZAÇÃO DO RISCO E A INSALUBRIDADE: UMA ÓTICA COMPARATIVA APRESENTADA PELO DIREITO ITALIANO

MARCO ANTÔNIO CÉSAR VILLATORE MIRIAM OLIVIA KNOPIK FERRAZ

Esta análise comparada se limitou ao estudo completo das respectivas Constituições, da Consolidação das Leis do Trabalho, do Código Civil italiano, da Norma Regulamentadora $\mathrm{n}^{\circ}$. 15 do Ministério do Trabalho e Emprego e do Decreto italiano n. 81\2008, intitulado "Testo Unico sulla salute e sicurezza sul Lavoro". Foi necessária a limitação do estudo a estes institutos e foram traçados com base nos dois últimos agentes e critérios, contidos em um ou outro ou em ambos. Alguns agentes de risco não estavam presentes em uma das normativas e foi necessário se buscar a legislação esparsa de ambos os ordenamentos para não deixar caracterizada uma lacuna inexistente. A pesquisa, apesar de certa amplitude, não abrangeu todos os agentes insalubres existentes, por mera questão de limitação física do estudo, entretanto, levantou-se a formação de bases suficientes para o entendimento de ambos os sistemas normativos, de seus padrões e perspectivas.

Do estudo das normativas básicas (NR-15 e Decreto $n^{\circ}$. 81/2008) contatou-se a complexidade da legislação italiana no que condiz a normas protetivas e maior abrangência de agentes insalubres, em detrimento da brasileira, mais concisa. Denota-se o enfoque diferenciado do sistema italiano em adotar a prevenção como patamar inicial e básico, enquanto a brasileira se volta principalmente à estipulação de graduações para determinar o percentual de adicional a ser pago.

Deste confronto e do estudo breve da legislação internacional a esse respeito, e em conformidade com a doutrina, observa-se a defasagem da política da monetização do risco aplicada no Brasil, e a necessidade da reformulação de paradigmas, principalmente pautado na unificação das normativas, à atualização, além do necessário direcionamento para a prevenção do risco e não à monetização deste.

Sendo assim, é urgente a mudança de paradigmas em todo o sistema brasileira, não somente a reforma legislativa, uma vez que a sua não aplicabilidade incumbiria na inutilização de um sistema, mesmo que considerado perfeito. Os ideais de prevenção e de proteção reflexos da cultura da saúde, são os primeiros pontos a ser implementados no ordenamento e na mentalidade dos aplicadores e receptores do Direito. 0 sistema se demonstra um conjunto e imagem espelhada da realidade e da iniciativa de cada órgão e membro.

Há a necessidade de reforma legislativa, certamente, para sua evolução e, principalmente, a sua adaptação à realidade e a parâmetros atuais desta e das normas regulamentadoras. Acima de tudo, há a necessidade da mudança de pensamento de todos que fazem parte desse sistema, do governante, que não aplica ou desenvolve políticas estatais preventivas; do empregador, que escolhe o caminho mais fácil do pagamento de adicional e 
A SUPERAÇÃO DA POLÍTICA DA MONETIZAÇ̃̃O DO RISCO E A INSALUBRIDADE: UMA ÓTICA COMPARATIVA APRESENTADA PELO DIREITO ITALIANO

MARCO ANTÔNIO CÉSAR VILLATORE MIRIAM OLIVIA KNOPIK FERRAZ

implementação mínima do EPI; dos órgãos de fiscalização, que não realizam visitas permanentes ou não voltam a atenção devida; do empregado que, muitas vezes, vítima das circunstâncias, não utiliza do EPI, não delata ações que colocam em risco sua saúde; do legislador que não realiza a produção e revisão normativa necessária e não produz legislações que estimulem as empresas (subsídios fiscais etc.) a cumprir e a ampliarem determinações preventivas e protetivas; do doutrinador jurídico, que, quando trata da matéria, adentra somente nos percentuais de adicional e não em questões que tanto afetam a realidade brasileira; da jurisprudência, muitas vezes enraizada, não vislumbrando que as atividades previstas na NR-15 do MTE não correspondem a todas as possibilidades.

O sistema é um conjunto, e somente com a adoção de medidas globais e generalizadas será possível a redução das estatísticas de doenças ocupacionais que tanto oneram a previdência social, destroem famílias e afetam a sociedade como um todo. Há a necessidade da atuação ampla dos membros da sociedade para a resolução de um problema com a complexidade que se vislumbra e, assim, valorizar os direitos tão proclamados como fundamentais e essenciais à vida humana, como o direito ao meio ambiente equilibrado (este inclui o laboral), à saúde, à dignidade humana e, principalmente à concretização e à elevação destes, através das mudanças de paradigmas e formulações, já comprovadas e exaustivamente defasadas.

\section{REFERÊNCIAS}

ALMEIDA, Raquel. Aplicação do Fator Acidentário de Prevenção: entre a intervenção estatal e a livre concorrência e iniciativa. Revista de Direito da Administração Pública, vol. I, nº I, 2012. Disponível em: http://www.redap.uff.br/index.php/redap/article/download/6/7. Acesso em: 16 maio 2016.

ALTALEX. Dipendente può rifiutarsi di lavorare se il datore non adotta le misure di sicurezza. 17 de novembro de 2005. Disponível em: https://goo.gl/OWxzWT. Acesso em: 21 fev. 2016.

ASSOCIAÇÃO BRASILEIRA DE HIGIENISTAS OCUPACIONAIS. Seminário da Pós-Graduação da FUNDACENTRO aborda a NR-15. Disponível em: https://goo.gl/6YglQy. Acesso em: 25 fev. 2017.

ASSOCIAÇÃO NACIONAL DE MEDICINA DO TRABALHO. Entidades enviam moção sobre a NR-15 ao Ministério do Trabalho. Disponível em: https://goo.gl/U1Cpl6. Acesso em 25 fev. 2017.

ASSOCIAÇÃO NACIONAL DE MEDICINA DO TRABALHO. Legislação. Disponível em: https://goo.gl/ONH1tX. Acesso em 23 fev. 2016.

BARROS, Alice Monteiro de. Curso de direito do trabalho. 9. ed. São Paulo: LTr, 2013. 
A SUPERAÇ̃̃O DA POLÍTICA DA MONETIZAÇ̃̃O DO RISCO E A INSALUBRIDADE: UMA ÓTICA COMPARATIVA APRESENTADA PELO DIREITO ITALIANO

MARCO ANTÔNIO CÉSAR VILLATORE MIRIAM OLIVIA KNOPIK FERRAZ

BITTAR, César; LOZOVEY, João Carlos do Amaral; ITANI, Alice; KULAY, Luiz Alexandre. A saúde do trabalhador: considerações sobre a gestão diante dos riscos e limites de tolerância à exposição da saúde. Revista de Saúde, Meio Ambiente e Sustentabilidade, São Paulo. Volume 6, n. 3, 2011. Disponível em: https://goo.gl/HGMCVD. Acesso em 26 fev. 2016.

BRASIL. Constituição Federal de 1988. Diário Oficial da União. Brasília: Senado Federal, 1988. Disponível em: https://goo.gl/UYNik9. Acesso em 19 jan. 2016.

BRASIL. Decreto $\mathrm{n}^{\circ} .84,16$ de abril de 1997. Transpõe para a ordem jurídica interna as Directivas do Conselho n. ${ }^{\circ}$ 90/679/CEE, de 26 de Novembro, e 93/88/CEE, de 12 de Outubro, e a Directiva n. ${ }^{\circ}$ 95/30/CE, da Comissão, de 30 de Junho, relativas à protecção da segurança e saúde dos trabalhadores contra os riscos resultantes da exposição a agentes biológicos durante o trabalho. Diário Oficial da União. Brasília: 16 abr. 1997. Disponível em: https://goo.gl/NUwQ6r. Acesso em: 23 fev. 2017.

BRASIL. Decreto $n^{\circ} .405$, de 11 de julho de 1998. Aprova a classificação dos agentes biológicos. Diário Oficial da União. Brasília: 11 jul. 1998. Disponível em: https://goo.gl/7bN2ut. Acesso em: 23 fev. 2017.

BRASIL. Decreto Lei $n^{\circ} .2$, de 04 de janeiro de 2001. Regula a utilização confinada de microrganismos geneticamente modificados, transpondo para a ordem jurídica interna a Directiva $n .^{\circ}$ 98/81/CE, do Conselho, de 26 de Outubro, que altera a Directiva $n .^{\circ}$ 90/219/CEE, do Conselho, de 23 de Abril. Diário Oficial da União. Brasília: 4 jan. 2001. Disponível em: https://goo.gl/GJKSwy. Acesso em: 23 fev. 2017.

BRASIL. Decreto Lei $n^{\circ} .46$, de 24 de fevereiro de 2006. Transpõe para a ordem jurídica nacional a Directiva n. ${ }^{\circ}$ 2002/44/CE, do Parlamento Europeu e do Conselho, de 25 de Junho, relativa às prescrições mínimas de protecção da saúde e segurança dos trabalhadores em caso de exposição aos riscos devidos a agentes físicos (vibrações). Diário Oficial da União. Brasília: 24 fev. 2006. Disponível em: https://goo.gl/yAJOuN. Acesso em 23 fev. 2017.

BRASIL. Decreto-Lei $n^{\circ} .180$, de 08 de agosto de 2002. estabelece as normas relativas à protecção da saúde das pessoas contra os perigos resultantes das radiações ionizantes em exposições radiológicas médicas e transpõe para a ordem jurídica interna a Directiva n.o 97/43/ EURATOM, do Conselho, de 30 de Junho, que revoga a Directiva n.o 84/466/EURATOM. Diário Oficial da União. Brasília: 8 ago. 2002. Disponível em: https://goo.gl/hSwEll. Acesso em 23 fev. 2017.

BRASIL. Decreto- Lei $n^{\circ} .182$, de 06 de setembro de 2006. Transpõe para a ordem jurídica interna a Directiva n. ${ }^{\circ}$ 2003/10/CE, do Parlamento Europeu e do Conselho, de 6 de Fevereiro, relativa às prescrições mínimas de segurança e de saúde em matéria de exposição dos trabalhadores aos riscos devidos aos agentes físicos (ruído). Diário Oficial da União. Brasília: 6 set. 2006. Disponível em: https://goo.gl/Twlg9s. Acesso em 23 fev. 2017.

BRASIL. Decreto-lei $\mathrm{n}^{\circ} .5 .452,1^{\circ}$. de maio de 1943. Aprova a Consolidação das Leis do Trabalho. Diário Oficial da União. Brasília: 1 maio 1943. Disponível em: https://goo.gl/OFBcva. Acesso em: 22 fev. 2017. 
A SUPERAÇÃO DA POLÍTICA DA MONETIZAÇ̃̃O DO RISCO E A INSALUBRIDADE: UMA ÓTICA COMPARATIVA APRESENTADA PELO DIREITO ITALIANO

MARCO ANTÔNIO CÉSAR VILLATORE MIRIAM OLIVIA KNOPIK FERRAZ

BRASIL. Lei $\mathrm{n}^{\circ}$. 11.934, de 05 de maio de 2009. Dispõe sobre limites à exposição humana a campos elétricos, magnéticos e eletromagnéticos; altera a Lei $\mathrm{n}^{\circ} \mathbf{4 . 7 7 1}$, de 15 de setembro de 1965; e dá outras providências. Diário Oficial da União. Brasília: 5 maio 2009. Disponível em: https://goo.gl/KTLjFA. Acesso em: 23 fev. 2017.

BRASIL. Ministério do Trabalho e Emprego. Norma regulamentadora $\mathrm{n}^{\circ}$. 6. Disponível em: https://goo.gl/ZnbcM. Acesso em: 22 fev. 2017.

BRASIL. Ministério do Trabalho e Emprego. Norma regulamentadora $\mathrm{n}^{\circ}$. 15. Disponível em: https://goo.gl/ZnbcMm. Acesso em: 22 fev. 2015.

BRASIL. Portaria $\mathrm{n}^{\circ}$. 1.036, de 15 de novembro de 2016. Altera a lista dos agentes biológicos classificados para efeitos de prevenção de riscos profissionais, aprovada pela Portaria $n^{\circ} 405 / 98$, de 11 de julho. Diário Oficial da União. Brasília: 15 nov. 2016. Disponível em:

https://goo.gl/8QZkrk. Acesso em 23 fev. 2017.

BRASIL. Turma Nacional de Uniformização da Jurisprudência dos Juizados Especiais Federais. Súmula n.09. Disponível em: https://goo.gl/TjFCri. Acesso em 25 jan. 2016.

BRASIL. SUPREMO TRIBUNAL FEDERAL. Súmula $\mathrm{n}^{\circ}$ 194. Disponível em: http: / / www.stf.jus.br/portal/jurisprudencia/menuSumarioSumulas.asp?sumula=3554. Acesso em: 19 mar. 2017.

CAMPAGNOLI, Adriana de Fátima Pilatti Ferreira. MANDALOZZO, Silvana Souza Netto. Uma (re)leitura do art. $7^{\circ}$., XXIII, da Constituição da República: Possíveis Alternativas para a Monetização do Risco com enfoque em atividades Insalubres. Disponível em:

https://goo.gl/fRg0D2. Acesso em: 10 jan. 2017.

DEIDDA, Beniamino. Le prospettive di riforma. Il progetto del Testo Unico. Palestra proferida no Seminário "Sicurezza sul lavoro: il sistema attuale e le prospettive di riforma", realizado no Palazzo Gazzoli, em Terni (Itália), em 16/06/2007.In: PORTO, Lorena Vasconcelos. A reforma legislativa em matéria de saúde e segurança no trabalho no direito italiano: uma análise crítica. Revista Brasileira de Estudos Políticos, v. 99, 2009. Disponível em :< https://goo.gl/g966sW>. Acesso em: 25 fev. 2017.

DELLA ROSA, Henrique V.; SIQUEIRA, Maria Elisa Pereira Bastos; COLACIOPPO, Sérgio.

Monitoramento Ambiental e Biológico. Apud OGA, Seizi; CAMARGO, Márcia Maria de Almeida; BATISTUZZO, José Antonio de Oliveira. Fundamentos de Toxicologia. São Paulo: Atheneu, 2008.

DIRITTO DEL LAVORO. Illegittimità del licenziamento per trascuratezza dell'obbligo di reperimento di mansioni consone al menomato stato di salute, semprechè sussistenti in azienda. Disponível em: https://goo.gl/fqh4FP. Acesso em: 21 fev. 2017.

FERNANDES, Fábio. Meio Ambiente Geral e Meio Ambiente do Trabalho: Uma Visão Sistêmica. São Paulo: LTr, 2009.

ITÁLIA. Costituzione Della Repubblica Italiana 1948. Disponível em: https://goo.gl/tSrHsq. Acesso em: 19 jan. 2016. 
A SUPERAÇÃO DA POLÍTICA DA MONETIZAÇÃO DO RISCO E A INSALUBRIDADE: UMA ÓTICA COMPARATIVA APRESENTADA PELO DIREITO ITALIANO

MARCO ANTÔNIO CÉSAR VILLATORE MIRIAM OLIVIA KNOPIK FERRAZ

ITÁLIA. Decreto n. 81 de 2008. Texto único de saúde e segurança no trabalho. Disponível em: https://goo.gl/ZJAfl4. Acesso em: $15 \mathrm{dez} .2016$.

ITÁLIA. Decreto nº 321 de 1956. Disponível em: https://goo.gl/RfguzE. Acesso em: 20 fev. 2017.

LIEBER, Renato Rocha. Saúde do Trabalho Rumo ao Ano 2000: Tendência na Avaliação dos Ambientes de Trabalho. Revista Brasileira de Saúde Ocupacional, v.19, no 74. São Paulo: FUNDACENTRO, 1991. Disponível em: https://goo.gl/WByK3R. Acesso em: 14 jan. 2017.

MINC, Carlos. A ecologia nos barrancos da cidade. In: VIANA, G.; SILVA, M.; DINIZ, N.(orgs). 0 desafio da sustentabilidade: um debate socioambiental no Brasil. São Paulo: Fundação Perseu Abramo, 2001.

NALINI, José Renato. O Juiz e a Constituição Ecológica. In: NALINI, José Renato (coord.). Juízes Doutrinadores. São Paulo: Millenium, 2008.

OLIVEIRA, Sebastião Geraldo de. Proteção Jurídica à Saúde do Trabalhador. 6a ed. São Paulo: LTr, 2011.

OLYMPUS. Amianto: responsabilità datore di lavoro. Disponível em: https://goo.gl/qcD9pM. Acesso em: 21 fev. 2017.

SANLORENZO, Rita. La tutela della legalità e della sicurezza sul luogo di lavoro nel sistema attuale. Palestra proferida no Seminário "Sicurezza sul lavoro: il sistema attuale e le prospettive di riforma”, realizado no Palazzo Gazzoli, em Terni (Itália), em 16/06/2007. In: PORTO, Lorena Vasconcelos. A reforma legislativa em matéria de saúde e segurança no trabalho no direito italiano: uma análise crítica. Revista Brasileira de Estudos Políticos, v. 99, 2009. Disponível em: https://goo.gl/g966sW. Acesso em: 25 fev. 2017.

SIMONIN, Camille. Médecine Du Travail. 1956, apud NOGUEIRA, Diogo Pupo. A insalubridade na empresa e o médico do trabalho. Revista Brasileira de Saúde Ocupacional, São Paulo, v. 12, n. 45, p. 40-51, jan/mar.1948.

UNIONCAMERE. Sentenza Corte di Cassazione: 17 febbraio 2003, n. 2.357. Disponível em: https://goo.gl/jHs35g. Acesso em: $21 \mathrm{fev} .2017$.

\section{COMO FAZER A REFERÊNCIA DO ARTIGO (ABNT):}

FERRAZ, Miriam Olivia Knopik; VILLATORE, Marco Antônio César. A superação da política da monetização do risco e a insalubridade: uma ótica comparativa apresentada pelo Direito Italiano. Revista Eletrônica do Curso de Direito da UFSM, Santa Maria, RS, v. 13, n. 1, p. 103-132, abr. 2018. ISSN 1981-3694. Disponível em: < https: //periodicos.ufsm.br/revistadireito/article/view/28143 >. Acesso em: dia mês. ano. doi: http://dx.doi.org/10.5902/1981369428143. 